\title{
O TOQUE RETAL EM CLINICA UROLOGICA
}

\author{
DR. AUGUSTO A. DA MOTTA PAChECo \\ 3.० Assistente
}

$\mathrm{Na}$ semiotica urologica não instrumental, o toque retal aparece como um método propedeutico de uma notavel importancia. Embora isso seja perfeitamente estabelecido e reconhecido entre os urologistas, na pratica corrente não é tão utilisado quanto devia ser. Isso acontece não somente entre os clínicos gerais, mas também, entre ns cirurgiões, embora em menor escala. E si o especialista, com tal método propedeutico obtém dados de grande valor para o diagnóstico, do mesmo modo o pratico geral deveria estar capacitado para saber usar tal método e obter tais dados.

O pratico geral, quer clínico quer operador, aquele que labuta na clínica numerosa e-trabalhosa do interior, aquele que não póde contar com o concurso de um especialista proximo e que na maioria das vezes é o único a precisar resolver tudo, tem necessidade de conhecer bem a pratica do toque retal. $\mathrm{O}$ auxílio e os ensinamentos advindos, orientariam para diagnósticos certos, as vezes faceis, para os quais ele mesmo poderia instituir terapeutica segura e criteriosa, fazendo prognósticos razoaveis.

E' muito comum o especialista receber doentes portadores de lesões genito urinarias, sem diagnóstico certo, às vezes até já com um prognóstico sombrio, em que depois de uma anamnése bem esmiuçada, no exame clínico não instrumental o toque retal conduz ao diagnóstico ou á exames complementarẹs que irão esclarecer e identificar o caso com certeza.

Não significa pelo que foi dito que ele seja mal conhecido. Simplesmente achamos que ele é um pouco esquecido.

Desejamos frisar a sua importancia, o seu valor e a necessidade de uma utilisação frequente, como uma rotina de exame. $O$ estudante que na Cadeira de Clínica Urológica recebe ensinamentos eminentemente praticos em relação ao toque retal deveria não esquecer o seu uso e o seu valor.

Sendo um método de exame tão simples, não necessitando praticamente de instrumental algum, todo o medico deveria faze-lo como rotina. 
Ha pouco tempo tivemos a oportunidade de examinar trés doentes. todos eles portadores de tumor da prostata. proviavelmente sarcoma, cujo sintoma inicial, ao lado de um emagrecimento acentuado e rapido, era uma obstrução intestinal aguda e posteriormente crónica. Pois ben, esses doentes fizeram numerosos exames de laboratório, especialisados e radiológicos, correram varios medicos. - ficaram sem diagnóstico, sem ao menos ter sido feito um simples toque retal, que haveria de revelar, como de fato revelou o diagnóstico. Do mesmo módo está a grande maioria daqueles doentes portadores de gota matinal. rebeldes á tratamento, que un simples toque faria diagnosticar prostatite crônica.

$O$ pratico geral muitas vezes não conseguindo estabelecer 0 diagnóstico pelo toque retal, poderá encaminhar o seu doente com mais acerto para o especialista.

Parece extremanente exagerada esta introdução ao estudo do toque retal. Somos sinceros en ennitir tal juizo, e todos aqueles que fazem a clinica diaria especialisada estarão de acordo com 0 nosso panto de vista.

Encarecida como generalisada a sua importancia para o pratico geral, clinico ou cirurgião, para o especialista, urologista, protologista e em menor grau ginecologista, a pratica do toque retal torna-se fundamental como já referimos.

Comtudo nós sómente vamos encarar quais os ensinamentos que o toque retal poderá dar ao urologista, e atravez deste prisma aos cutros praticos.

O toque retal deverá ser feito na seriação habitual do exame do paciente. Após uma anamnése cuidadosa, um exame clinico geral, chega-se ao.exame clinico não instrumental do aparelho urogenital, onde o toque retal está colocado.

Como dissemos, este metodo propedeutico deve ser indicado como rotina.

Não ha contraindicação á pratica do toque retal. Mesmo nos processos agudos intensos, ele poderá ser usado sem dano algum para o paciente, desde que sejam simples e unicamente examinadas as estruturas subjacentes com doçura e não seja feita a expressão de orgão algum. A expressão sim. tem a sua contraindicação nos processos agudos acentuados.

Além das caracteristicas objetivas apreendidas pelo dedo que palpa e os fenomenos subjetivos produzidos, pelo toque retal poderemos fazer a expressão das secreções prostaticas, vesiculares e da glandula de Cowper, sua colheita posteriormente e exame bacterioscopico e bacteriologico. Os exames dessas secreçōes que poderemos assim fazer, são de grande importancia no diagnostico dos processos inflamatorios desses orgãos, principalmente nos processos cronicos. Do mesmo modo são usados como criterio de cura. Apóz uma lavagem da uretra anterior, ou uretro vesical, ou simplesmente apóz a miç̧ão, fazemos a expressão prostato-vesicular e colhemos o material 
no meato uretral. Mas em certos casos a secreção se coleta na bexiga de sorte que nada chega ao meato uretral. Será melhor então, fazer uma cuidadosa lavagem uretro vesical, deixar liquido na bexiga, fazer a expressão prostato vesicular e colher o liquido da micção em vaso esteril, para centrifugação e exame do sedimento. Comtudo para um maior criterio de certeza poderemos usar os metodos de Wolbarts, dos 4 calices ou o de Young dos 7 vasos. O de Wolbarts é mais simples e preferivel. Lava-se a uretra anterior, colhendo-se a agua de lavagem que encerra as secreções dessa porção da uretra. Cateterisa-se a bexiga colhendo-se a urina ahi contida pela sonda. Enche-se a bexiga com uma solução. Retira-se a sonda, o paciente urina, eliminando a secreção da uretra posterior. Por fim faz-se a expressão prostato vesicular, e o paciente novamente urina, para exame das secreções ahi contidas. Deve-se fazer a expressão prostatica, sempre da periferia para o centro esvasiando os ductos prostaticos.

Além de sua valia como metodo de diagnostico, pelo toque retal atinge-se prostata e vesicula seminal para tratamento, pela massagem prostato-vesicular e consequente drenagem dos dutos prostaticos e da vesicula seminal.

Varias são as posições em que o paciente é colocado para ser submetido a este metodo semiologico. WILDBolz e EISENDRATH são partidarios do decubito lateral, com as coxas bem flectidas sobre

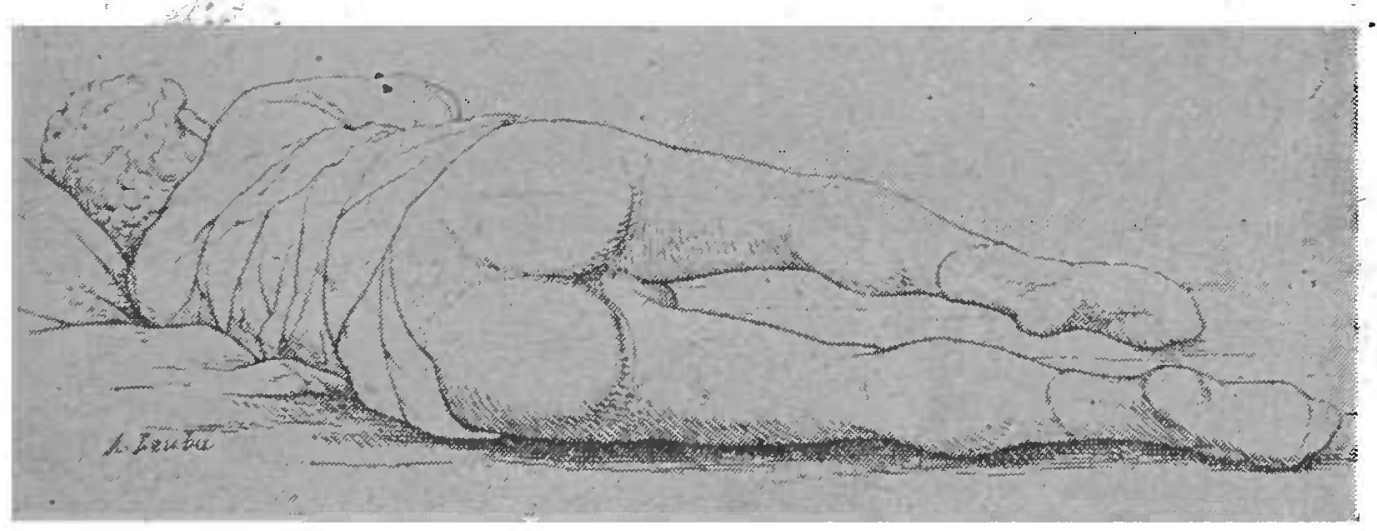

Decubito lateral (BAILEY)

o abdomen, asseverando que nessa posição as vesiculas são bem atingidas e ha maior comodidade para o paciente, principalmente quando ele se encontra enfraquecido. Demais, si ele tiver um desfalecimento, uma lipotimia, nada sofrerá, pois está perfeitamente apoiado. $\mathrm{Na}$ posição ginecologica, em decubito dorsal, as coxas bem flectidas e afastadas tambem atinge-se bem as estruturas que se prètende examinar. Posição desfavoravel é a de pé com o tronco flectido. A posição genupeitoral é excelente por se poder atingir profundamente, mas tem o inconveniente de queda do paciente em caso de lipotimia. 


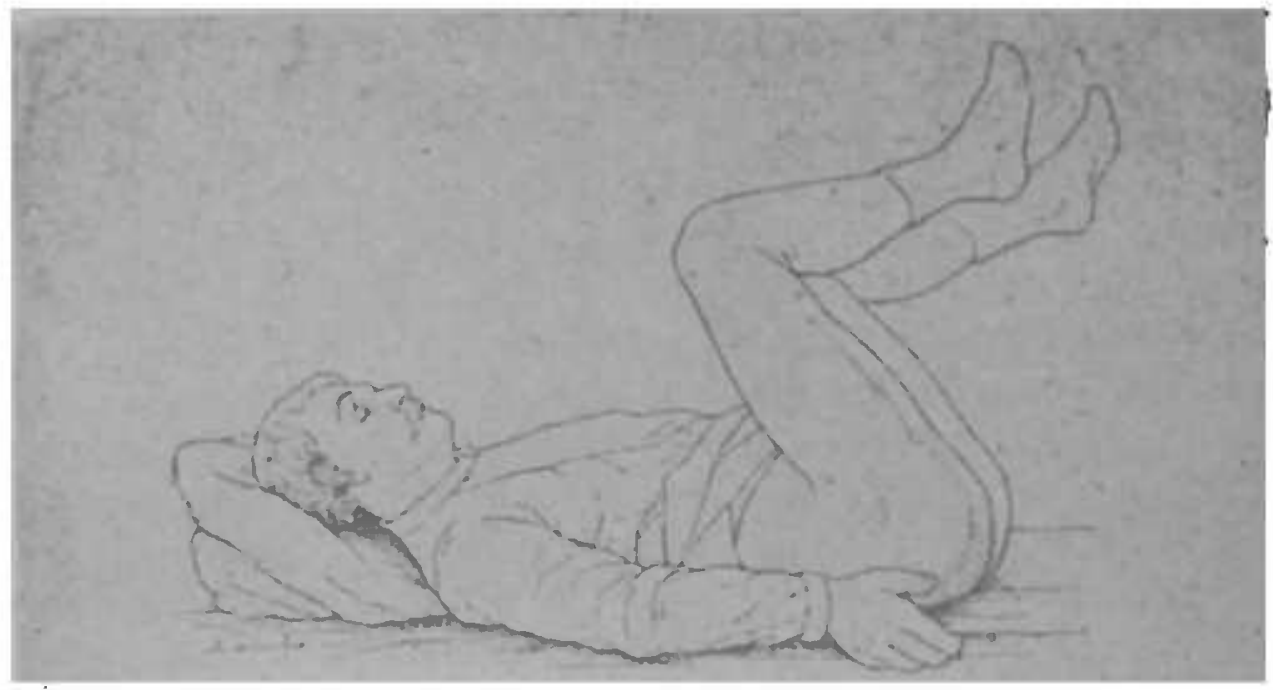

Decubito dorsal, coxas bem flectidas. (BAILzy)

Deve-se usar para proteção do dedo, ou uma luva bem ajustada uu uma dedeira, facil de ser carregada pelo clinico. O dedo indi-

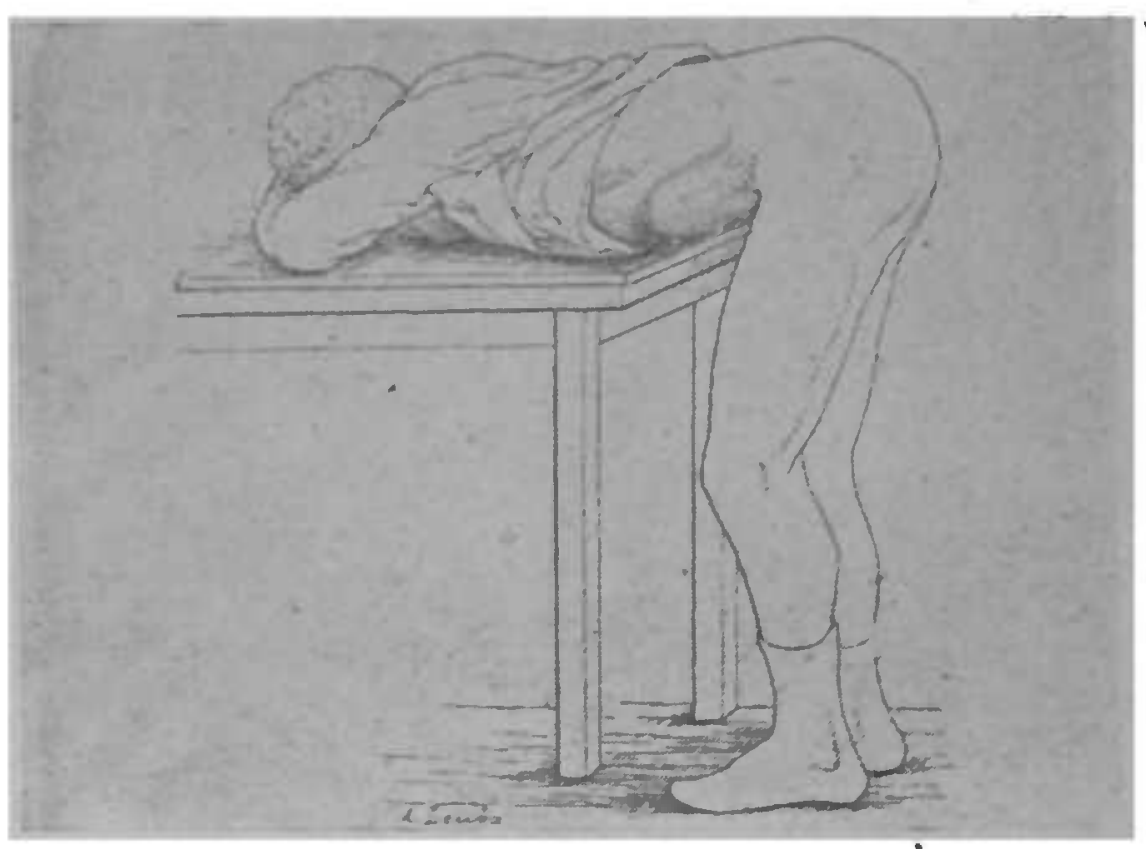

De pé. tronco flectido. (Barley)

cador, que é o usado, deverá estar bem lubrificado para uma introdução facil. suave e que portanto não cause mal estar ao paciente. Deve-se ao introduzir o dedo, afastar as nadegas, franquear docemente o esfincter anal, procurando não arrastar durante a sua introdução os pelos circumjacentes.

Ha necessidade do examinador se adaptar á palpação com qualquer uma das mãos. pois nem sempre é possivel a palpação só com a mesma. Não só em relação a posição do proprio doente, mas 
tambem em relação ao orgão a ser palpado que é mais facilmente atingido por esta ou aquela mão.

O toque retal nunca deverá ser demorado. O medico deverá adquirir uma pratica tal que com certa rapidez ele faça um exame seguro de todos os orgãos atingiveis, e guarde o resultado, fazendo
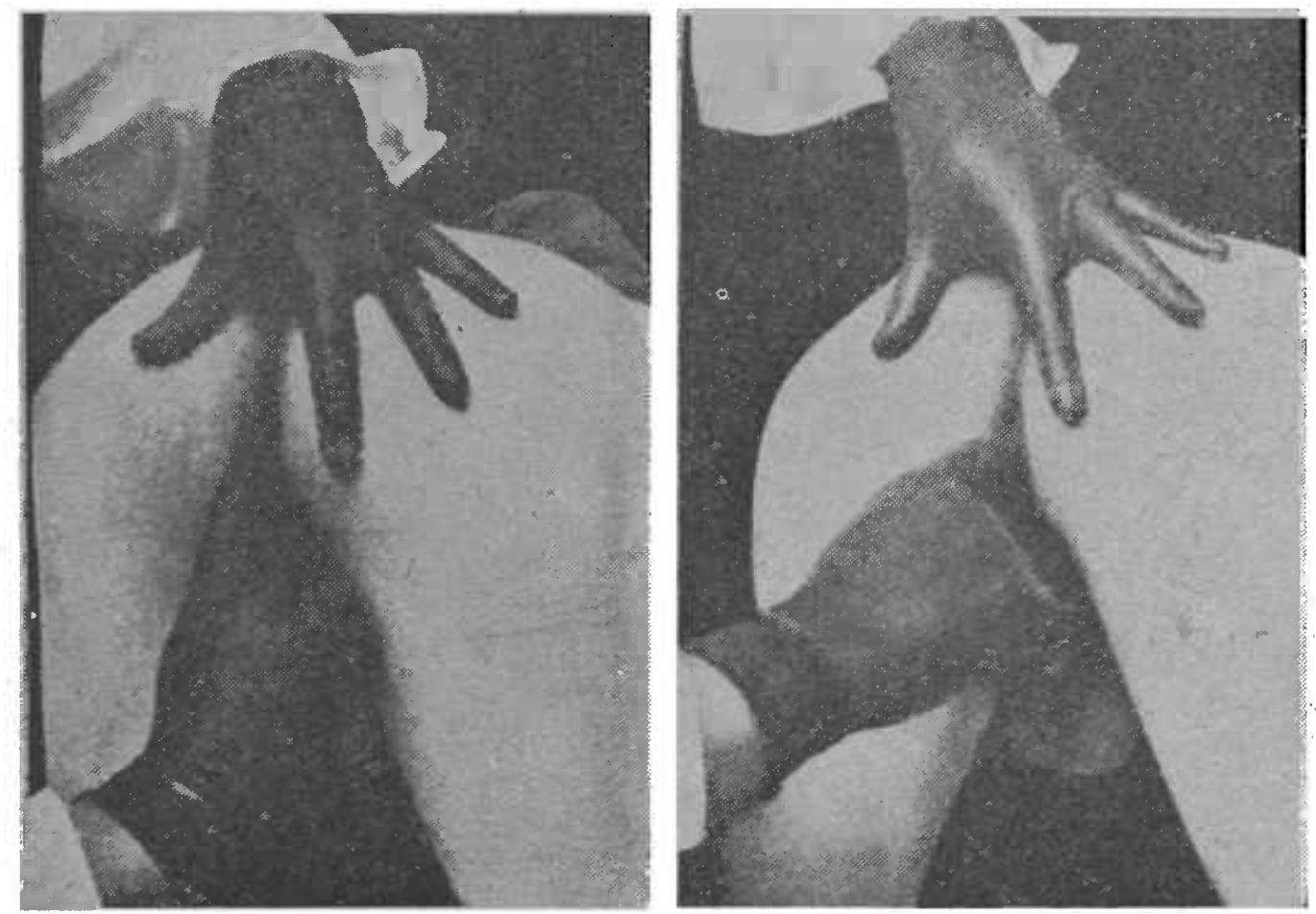

Posiçāo genu peitoral. (BAILEY)

mentalmente um esquema. Feito o toque ele deverá descrevel-o imediatamente ou melhor, esquematisal-o. Para esse fim ha modelos, cujo tipo é o diagrama de Young sobre o qual se fixará o achado digital.

Não somente nos casos de diagnostico duvidoso, deve-se fazer mais de um toque retal, mas tambem para uma avaliação segura da

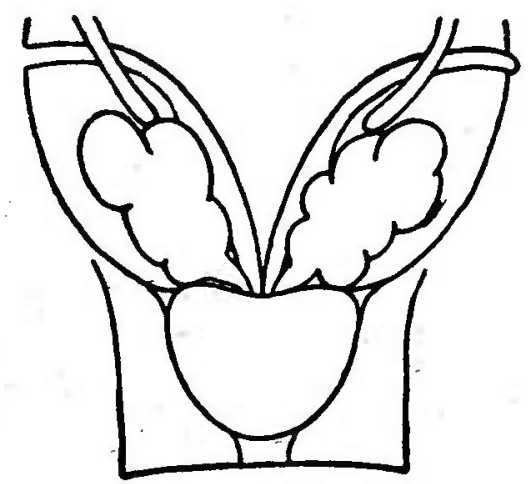

Diagrama de Yousg. (EISE:rdrath)

evolução de um caso que já tenha diagnostico estabelecido. Ha casos em que se deve emitir o diagnóstico depois de varios exames espaçados, e em alguns sómente apóz tratamento de prova. 
No toque retal vamos examinar a mucosa retal, a prostata, vesiculas seminais, uretra posterior, trigono e fundo vesical, extremidade inferior do ureter, canal deferente e glandula de Cowper.

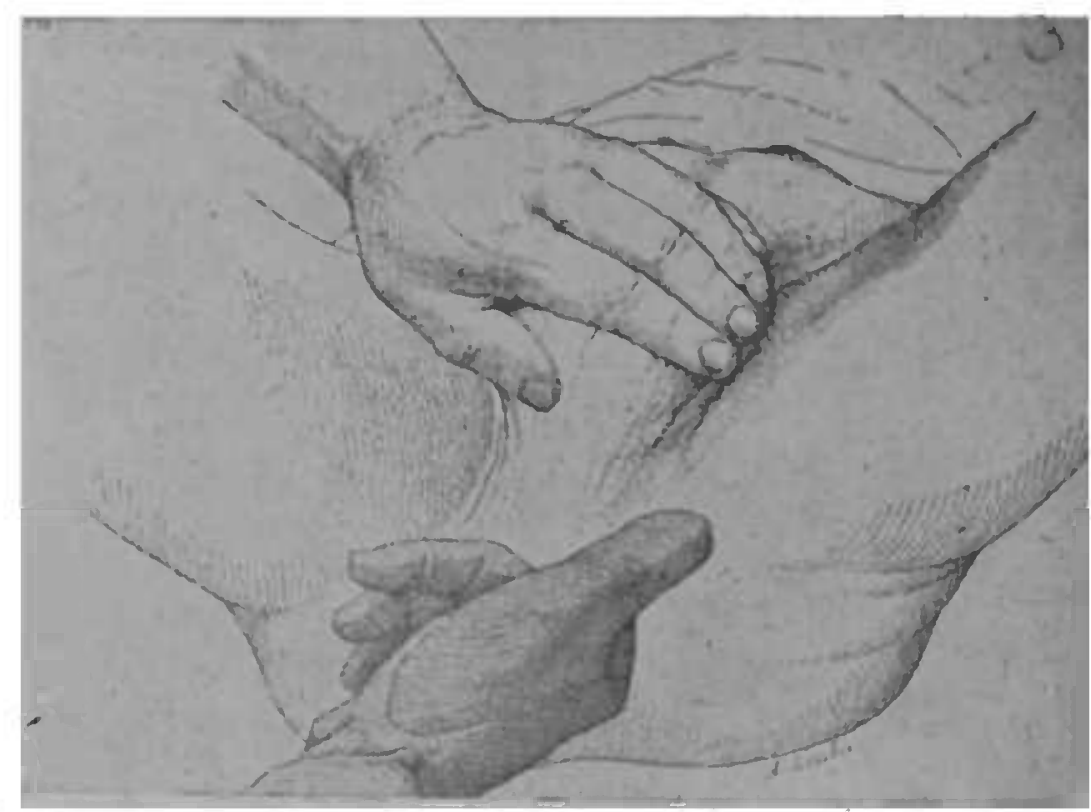

Palpaçăo da glandula de Cowper. (Bailey).

Para a palpação das glandulas de Cowper usamos o metodo bidigital. Introduz-se o indicador no réto e com o polegar no perineo anterior procura-se sentir de cada lado da linha mediana, do bulbo uretral, simetricamente, cada uma das glandulas de CowPER. Em estado normal elas não são palpaveis.

O dedo introduzido no réto, após sentir as caracteristicas da. mucosa retal, na parede anterior do réto e tambem nas laterais, palpa

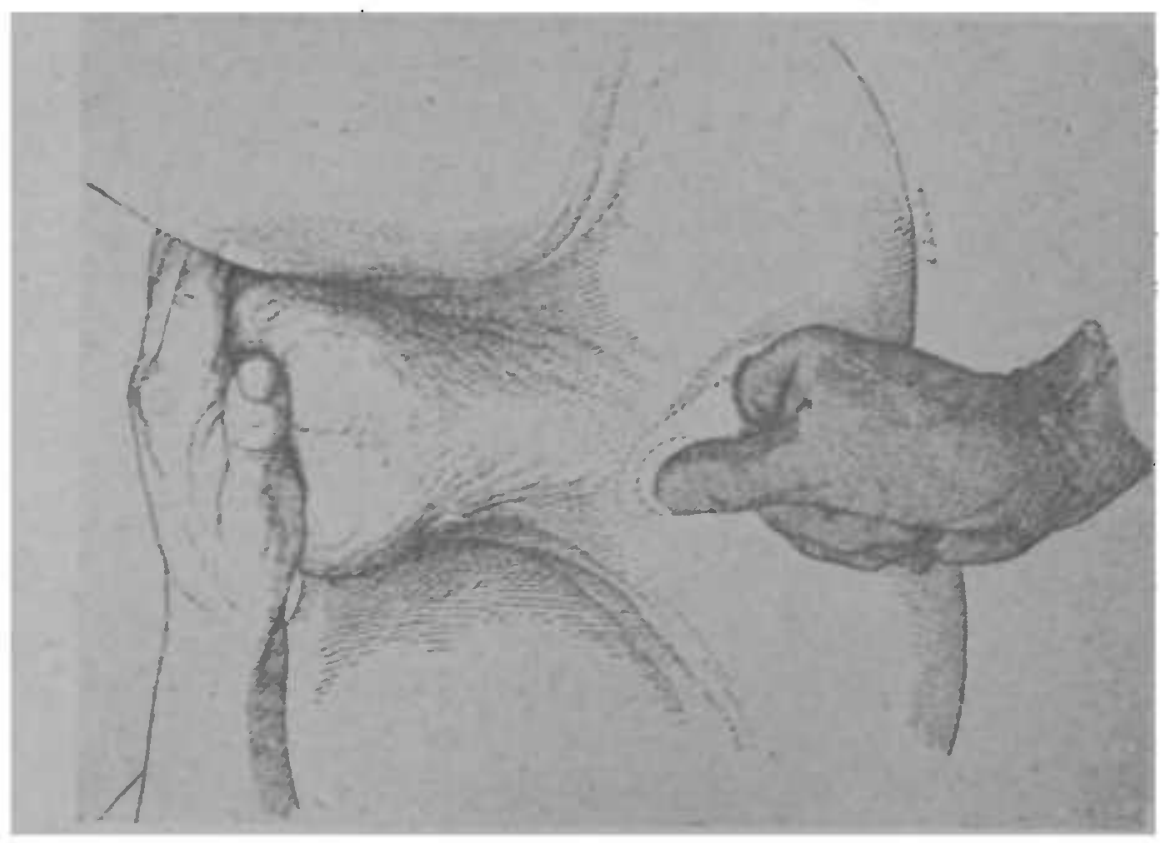

Palpação da glandula de Cówrex. (Barley). 
na parede anterior, indo de baixo para cima. A prostata situada a 4 ou $5 \mathrm{cms}$. do orificio anal, sob a forma de dois lobos ovoidais, obliquamente dirigidos de cima para baixo e de fóra para dentro, nitidamente limitados em relação aos tecidos circumjacentes, de consistencia elastica e firme, fazendo discreta saliencia na mucosa retal, simetricos, unidos em sua parte inferior, separados na superior por ım espaço triangular de apice inferior, o chamado sulco mediano, medindo mais ou menos no conjunto $3 \mathrm{cms}$. $x 4 \mathrm{cms}$. $O$ dedo que explora atinge-a em todo o contorno. A prostata normal é indolor á palpação. A uretra posterior, na parte mediana pre-prostatica $\mathrm{e}$ acima da prostata, em que sómente nos estados patologicos poder-

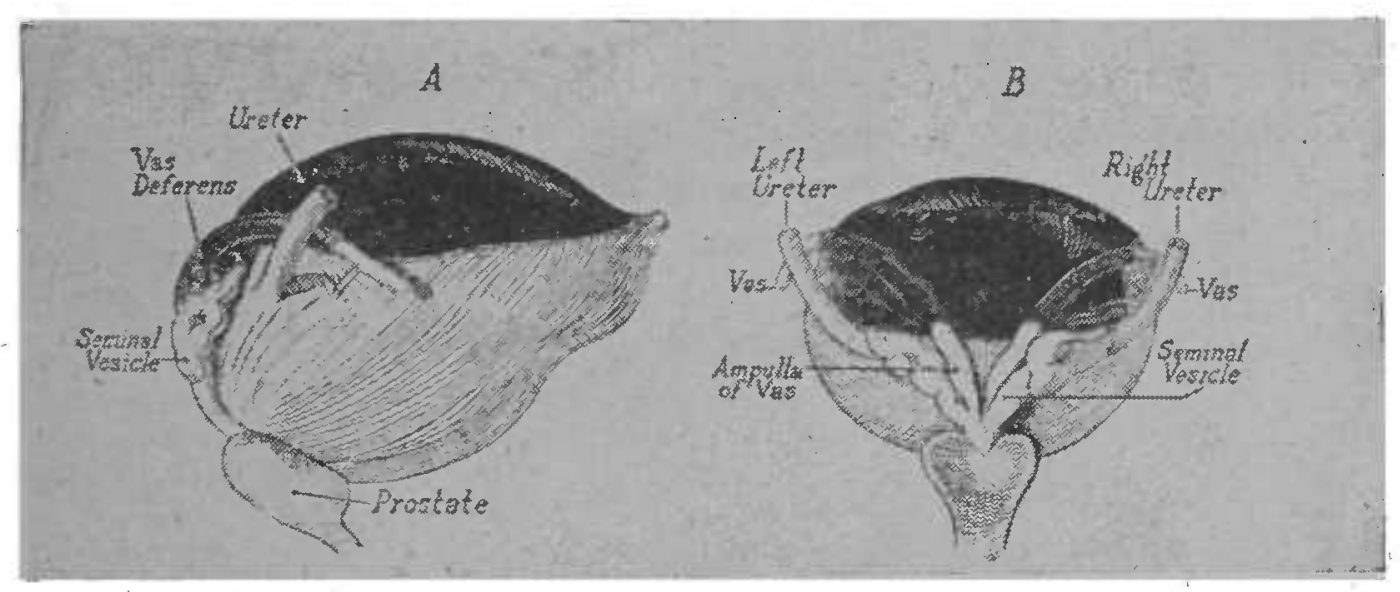

Resenha anatomica. (EISENDRATH)

se-há notar alterações objetivas e produzir perturbações subjetivas no paciente. Vesiculas seminais. Muitos autores acham que as vesiculas seminais quando normais não são palpaveis. Desse modo toda vesicula palpavel é considerada patologica. Outros, comtudo, acham que a vesicula seminal poderá ser palpada em estado normal, como um corpo alongado, divergente, acima e nos angulos da prostata, mole, elastico, delgado, liso, sem infiltração e não doloroso. Canal deferente. Acima e para dentro da vesicula seminal sómente nos casos patologicos ha autores que dizem tèr palpado o canal deferente como um cordão divergente. Ureter. Para fóra das vesiculas poder-se-ha palpar embora raramente, nos casos patologicos, o ureter. Mas o que se produz em geral é a dôr situada no chamado ponto ureteral inferior, que corresponde á entrada do ureter na bexiga, havendo até a produção do reflexo uretero vesical de BAzÝ. Trigono e fundo vesical. Para cima da prostata póde-se atingir o trigono e o fundo vesical. Neste particular é conveniente associar ao toque retal o palpar hipogastrico.

Seguindo a mesma seriação ao atingir os diferentes orgãos em estado normal, tambem vamos passar em revista os caracteres semio- 
ticos dados pelo toque retal de cada um deles nos diferentes proccisos patologicos. Vamos referir unicamente sinais semioticos dados pelo toque retal, procurando fazer o diagnostico diferencial só com estes sinais, e principalmente com os que forem mais caracteristicos. Não pretendemos fazer o diagnostico diferencial completo das diversas lesōes patologicas desses orgãos. Chamamos a atenção mais uma vez para o fato, que si o toque retal é um notavel metorlo semiotico, ele na maioria das vezes é um exame complementar, como o é quasi todo metodo semiologico. Ele deverá sempre estar relacionado com a anamnése, com o exame geral, com o exame do aparelho urinario e com o exame do restante do aparelho genital. Demais si o diagnostico nesse ponto ainda não estiver ou estabelecido ou completado, ele deverá, juntamente com os dados anteriores, orientár para exames mais completos e mais complexos, exames instrumentais, tais como o cateterismo uretral, cístoscopia, uretroscopia, e radiografia em suas diversas modalidades. A nossa finalidade no 1. resente artigo é chamar a atenção para o valor do toque retal, expor os seus principios e tecnica e estabelecer os elementos fundamentais que ele fornece ao diagnostico.

Glandula de Cowper - Com o metodo palpatorio que já assinalamos podemos localisar os processos inflamatorios agudos e cronicos da glandula de Cowper. Nas cowperites agudas ha uma tumefação um pouco visivel, que eleva ligeiramente a pele do perineo, atraz do escroto, ao lado da linha mediana, alongada de diante para traz que é perfeitamente identificada pelo indicador no réto e 0 polegar perineal. $\mathrm{Ha}$ ás vezes certa dificuldade em se diferenciar a cowperite aguda do abcesso urinario perineal. Na cowperite cronica percebe-se nitidamente uma pequena massa do tamanho mais ou menos de um grão de ervilha, situada lateral ao bulbo uretral e atraz da raiz do escroto. A tuberculose da glandula de Cowper apresenta o mesmo quadro palpatorio da cowperite cronica.

Mucosa retal - A mucosa retal apresenta alterações nos processos dos orgãos situados em sua frente. Assim nas supuraçōes agudas intensas da prostata ou da prostata e das vesiculas seminais, ela se apresenta edematosa. Nas fistulas uretro retais ou uretro prostato retais de longa duração póde-se reconhecer a presença de um orificio, quando de pórte relativamente grande, ou então uma zona em que ha um botão de granulação bem saliente. Nas neoplasias da prostata, principalmente na chamada carcinose prostatopelviana, a mucosa retal encontra-se infiltrada e aderente, e a parede retal fixa. Esta infiltração estende-se de cada lado na direção de cada fossa isquio retal. 
Prostata - Devido a frequencia espantosa das lesões da prostata, no jovem os processos inflamatorios e no velho os de hipertrofia e neoplasia, torna-se muito dificil em doentes de um ambulatorio de molestias do aparelho urogenital, encontrar um que apresente uma prostata perfeitamente normal. Si muitas vezes o doente ao ser examinado não apresenta processo algum em evolução, ele, comtudo póde ter um processo cicatricial de uma lesão anterior. Demais ha uma variação grande èm relação aos caracteres normais da prostata. Desse módo torna-se necessario que se procure palpar prostata normal, para se poder perceber nitidamente uma lesão inicial. Óra, muitas vezes tal não acontece, e é bem comum aqueles que já fazem a pratica do toque rełal com desambaraço relativo e que ainda não tiveram a oportunidade de fazer uma unica vez um toque em individuo isento de lesão prostato-vesicular. Julgamos de real interesse e absolutamente necessario: tocar anexos normais.

As diversas entidades nosologicas produzem alterações na glandula prostatica que poderão ser unicas, mais raras, ou associadas, mais frequentes. Estas alterações estão em relação ao volume, forma, consistencia, superficie, limites, sensibilidade e mobilidade. Só o volume é aumentado na atonia prostatica simples, naqueles que já sofreram uma prostatite, diminuido na atrofia congenita da prostata. $O$ volume e a consistencia encontram-se alterados no adenoma da prostata que atinge somente as glandulas periuretrais laterais, em que ha aumento dos lobos e a consistencia é carnosa (adenoma puro) ou dura (fibroadenoma). O mesmo acontece no calculo prostatico (consistencia petrea), mais nitida quanto maior e unico, e no quisto em que ora é dura ora flutuănte. $\mathrm{O}$. volume, a consistencia e a fórma estão juntamente alterados no adenoma das glandulas periuretrais laterais e sub-cerviciais, em que além do aumento do orgão da consistencia carńosa ou dura, ha tambem um apagamento ou desaparecimento do sulco mediano. O volume, a consistencia, a superficie e a sensibilidade encontram-se alterados na prostatite aguda e cronica, no neoplasma localisado ainda, no calculo prostatico, no quisto e na tuberculose. Aqui à superficie poderá apresentar-se com irregularidades em um unico lóbo, formando um nodulo, ou nos lóbos, e em varios pontos apresentando-se cheia de pequenos nodulos, óra mais óra menos confluentes. O volume, consistencia, superficie, sensibilidade, fórma, limites, e mobilidade estão todos alterados no neoplasma da prostata, e de uma maneira acentuada no esquirro da prostata. O volume, a consistencia, a forma e a sensibilidade estão alterados no abcesso da prostata, no adenoma associado á prostatite aguda ou cronica, no abcesso e no quisto.

Vistas no conjunto estas alterações, vamos procurar esquematisar, na medida do possivel, o que as diferentes molestias fornecem an toque retal.

Anomalias - Atrofia da prostata. Diminuição mais ou menos acentuada do orgão, tão intensa ás vezes que para a percepção da 
prostata pelo dedo que palpa è necessario colocar um cateter metalico curvo na uretra. As vezes esta atrofia atinge sómente um dos lóbos. Agcucsia da prostata. Nada se palpa na agenesia total. Palpa-se somente um dos lóbos na agenesia parcial.

Processos inflamatorios. Na prostatite catarral aguda, ha unn aumento discreto do volume do orgão, que é anolecido e um pouco doloroso. $\mathrm{Na}$ congestão da prostata nos individuos masturbadores o achado é o mesmo. Na prostatite folicular aguda, ha um aumento de volume do orgão, com areas de maior consistencia, localisadas ou confluentes, em um ou ambos os lóbos, e com acentuada dôr á palpação. Prostatite parenquimatosa aguda, apresenta um aumento acentuado do orgão, que está duro, ás vezes com pontos menos consistentes e muito doloroso. No abccsso prostatico ha um aumento acentuado da glandula, que faz salientar a parede anterior do réto, que se torna achatada, elastica, depressivel, tensa e extremamente dolorosa, ás vezes até pulsatil. ' $\mathrm{O}$ abcesso constituindo-se torna-se móle e flutuante. O abcesso poderá atingir toda a glandula ou se localisar em um lóbo. Quando ele se esvasia pela uretra reconhece-se perfeitamente uma depressão nesse ponto devida a perda de tecido prostatico. Isso torna-se muito mais evidente quando o abcesso se instala em uma prostata adenomatosa. Quando o abcesso está aberto no réto, reconhece-se não sómente a ulceração da parede retal como tambem a presença de sangue e pus no réto. Deve-se nos processos supurativos agudos fazer o toque com grande delicadeza. $\mathrm{Na}$ prostatite cronica folicular, ha leve aumento da glandula, com asimetria, ás vezes aumento de consistencia em toda a glandula ou em certos pontos, com zonas anolecidas e ligeiramente dolorosa. Na prostatíte cronica supurativa, ha aumento de volume, com zonas amolecidas, ás vezes até de tamanho de uma avelã, em geral multiplas, circumdadas por zonas de tecido duro e bastante dolorosa. $\mathrm{Na}$ prostatite cronica esclerosante nota-se pouco aumento de volume ou a prostata tem o tamanho normal, consistencia dura, lisa ou levemente loculada e discretamente dolorosa.

Devemos acentuar mais uma vez que nos processos inflamatorios prostata, ha uma variação notavel do quadro de dia para dia, o que é um precioso meio de diagnostico.

Tuberculose da prostata. O toque é de valor tanto nas fases tardias como nas precoces, onde é excepcional encontrar-se uma glandula normal. Nota-se infiltrações nodulares individualisadas, de tamanho variavel, de grande consistencia e de fórma constante, sem variação alguma. Ha uma diminuição da mobilidade da glandula, que por conseguinte está ligeiramente fixa. Algumas vezes ha ao lado dos nodulos um endurecimento difuso do resto do orgão. Outros vezes a glandula apresenta-se como uma massa dura, difusa, com numerosos pontos amolecidos correspondentes ás cavernas.

$\mathrm{Na}$ sifilis, na actinomicose e na bilharzioze não ha quadro caracteristico. Assemelham-se, em geral, á prostatite cronica folicular on do tim esclernen. 
Litiase prostatica. Quando são muito pequenos, e pouco numerosos, ha um aumento de volume, da consistencia e ligeiramente da sensibilidade, não havendo portanto nada de caracteristico. Pelo contrario quando são numerosos, ha um aumento de volume do orgão, que é duro, simulando a dureza de pedra, e ás vezes hota-se a crepitação que é tipica. Sendo um unico calculo grande em um lóbo, chega-se até a perceber os seus carecteres de corpo estranho, de consistencia petrea, e mesmo as irregularidades de sua superficie, porque a prostata fica reduzida a uma verdadeira cascá.

Adenoma. Devemos inicialmente assinalar que ha casos, embora excepcionais, nos quais as massas adenomatosas se desenvolvendo unicamente para dentro da bexiga, não se poderá reconhecer alteração tipica pelo toque retal. Na maioria das vezes, contudo, reconhece-se o adenoma pelo aumento de volume do orgão, ás vezes tão acentuado; que não se poderá atingir o seu limite superior, com apagamento e até desaparecimento do sulco mediano, limites bem definidos, mobilidade nitida, superficie lisa, asimetria quando o processo se assenta mais acentuadamente em um dos lóbos, consistencia carnosa, discretamente mais firme que o orgão normal (adenoma) ou então ligeiramente endurecida (fibroadenoma), uniforme e indolôr. No adenoma puro não ha dôr, mas no adenoma associado a uma prostatite aguda ou cronica ou a um abcesso prostatico, ha dôr ao lado das caracteristicas palpatorias que já assinalamos. Embora rara, podérá haver coexistencia de adenoma com túberculose de prostata o que poderá dificultar o diagnostico. $\mathrm{Na}$ degeneração carcinomatosa do adenoma, tendo sido feito o exame previamente, notar-se-ha uma modificação em relação áos limites que se tornam imprecisos, á mobilidade que desaparece e á consistencia que ficará lenhosa.

Quisto. Prostata aumentada de volume, ás vezes notavelmente, com flutuação, sem fenomenos inflamatorios e de superficie lisa.

Carcinoma. Ha aumento de volume, dôr, dureza lenhosa, superficie muito irregular, lobulada ou não lobulada, com nodulos mais firmes que os tecidos adjacentes, desaparecimento da nitidez dos contornos, invadindo as estructuras circumvisinhas até a fossa isquio retal, principalmente as vesiculas seminais, como um blóco tumoral unico, completamente fixo, com enfartamento dos linfaticos da visinhança mais os da extremidade superior das vesiculas seminais e paredes laterais da pelvis.

Sarcoma. Aumento de volume desusado, deslocando a bexiga e empurrando a parede retal anterior, de consistencia duro elastica, variando do móle (não flutuante como no abcesso) ao duro (não tão acentuado como no carcinoma), superficie irregular, fixo. A variação é sempre para aumento nitido no proximo toque tempos apóz.

Vesiculas seminais - Já referimos a discordancia entre os autores em relação a possibilidade de serem as vesiculas normais pal- 
paveis. Repetimos que vesiculas normais. com certa atonia e distensãu. ou nos individuos que são continentes por algum tempo, såo. palpaveis.

A.jomalias. Ausencia uni ou bilateral.

Procissos inflamatorias. I'esiculite aguda. Tunefação irregular. muito dolornsa. com séde caracteristica latero supraprostatica. Havendo perivesiculite os limites são imprecisos. Nos processos nencs intensos ha simplesmente um discreto endurecimento e sensihilidiade. Poderão ambas serem envolvidas pelo processo ou unicamente uma delas. I'isiculite cronica. Infiltração firme da parede vesicular. que se apresenta tensa e sensivel á pressão.

Tubcrculosc. Infiltração consistente, pouco sensivel, cọ̣ forma tuberosa do orgão que se apresenta fixo. As vezes juntamente coin a prostata, e os linfaticos infartados, a vesicula fórma um bloco espesso, irregular, fixo e pouco doloroso.

Calculose. Embora rara, nota-se um corpo de consistencia petrea na séde habitual da vesicula seminal.

Cancer e sarcoma. A vesicula, en geral, é uma parte do blóco prostato vesicular assinalado.

Uretra posterior - Nos processos agudos de uretra posterior sem ainda lesāo dos anexos, póde-se notar uma dôr mediana intensa para cima da prostata, devida á compressão da uretra contra a sinfise pubiana. Na litiase da uretra posterior, a litiase prostatica exogena. tambem poder-se-ha notar um corpo estranho, de consistencia petrea, mediano e pré ou supra prostatico.

Canal deferente - Nos processos inflamatorios agudos ou cronicos do canal deferente, nota-se para dentro da vesicula seminal e para cima, ou uma zona dolorosa ou um cordão, espessado, duro e doloroso.

Ureter - $\mathrm{O}$ ureter poderá ser atingido em sua porção justa. vesical pelo dedo introduzido no réto, sempre para fóra das vesiculas. seminais. Comtudo, raramente consegue-se ter uma sensação palpatoria do proprio ureter a não ser que ele se encontre muito espessado, ou muito dilatado, ou ainda que nesse ponto esteja detido um calculo em sua migração para a bexiga. Mais frequente, embora muitas. vezes enganadora, é a pesquiza da sensibilidade nesse ponto justavesical. Nos processos inflamatorios agudos, principalmente, do tracto alto. ele se apresenta doloroso, aparecendo tambem uma necessidade imperiosa de urinar. que constitue o reflexo uretero vesical de Bazy.

Trigono e fundo vesical - $\mathrm{Na}$ retenção aguda de urina o trionno a fundn veciral cān centidnc fazendn saliencia no rétn Na 
pericistite nota-se quer um espessamento dessa zona com intensa dôr, quer mesmo a presença de flutuação revelando uma coleção. Do mesmo modo nos tumores vesicais poder-se-ha notar uma zona de espessamento, de infiltração no fundo, muitas vezes associada a lesão semelhante prostato-vesicular. Melhor comtudo será associar ao toque retal o palpar hipogastrico. Deste modo pode-se perceber corpos estranhos mais ou menos volumosos entre os dois dedos. Foi deste modo que mostramos a uma das ultimas turmas de alunos da cadeira de Clinica Urologica, volumoso calculo vesical nitidamente perceptivel. Da mesma maneira até residuo vesical abundante poderá ser egualmente percebido assim como uma prostata de tamanho exagerado.

Associamos tambem o toque retal ao palpar intravesical com a bexiga aberta, no exame do conteudo prostatico, para melhor reconhecimento de litiase prostatica.

Tambem no descolamento do adenoma prostatico á Freyer, o dedo" introduzido no réto para apoiar a prostata é de grande auxilio.

Já referimos á combinação entre o toque retal e o cateterismo uretral com sonda metalica curva.

Devemos assinalar ainda que nós traumatismos intensos da bacia, com lesões osseas acentuadas, pelo toque retal poderemos reconhecer fragmentos osseos bombeando no réto, o que é de importancia como subsidio ao diagnóstico das lesões do aparelho urogenital nesses casos. Demais tambem com o dedo no réto poderemos ter um ponto de - apoio na tentativa de redução dos referidos fragmentos osseos.

Toque vaginal - Como simples adenda vamos referir o que o toque vaginal poderá revelar nas lesões do aparelho urinario. Nem. queremos fazer alusão ao toque vaginal nas lesões do aparelho genital que é de tão grande importancia para o diagnostico dessas lesões, porque escapa á finalidade do presente trabalho que abrange somente as lesões do aparelho urogenital do homem e urinario da mulher. Frisamos, comtudo, que a intima relação entre as lesões do aparelho urinario e genital da mulher, exige que o exame do aparelho genital feminino seja obrigatorio nas afecções do aparelho urinario.

O toque retal na mulher não traz dados suficientes para conclusões diagnosticas das lesões do aparelho urinario.

Posto isto, pelo toque vaginal vamos examinar a uretra, a bexiga e o ureter inferior.

A uretra é atingida pelo indice introduzido na vagina com a polpa voltada para o pubis. Pela sua expressão obtem-se a secreção no meato, pela sua palpação notar-se-ha espessamento da parede uretral, orificio de fistula, corpos estranhos e tumores.

A bexiga é examinada pelo fundo de saco vaginal anterior, palpando-se o trigono e o fundo vesical, onde se notará corpos estranhos 
e calculos, cistoceles, orificios de fistulas vesica-vaginais e tumores. Porle-se tambem fazer a palpaşão combinada vngino hipogastrica.

Pela vayina tambem atinge-se a cxtrcmidade infirior do uriler, obtendo-se os mesmos dados já assinalados.

Finalisamos isti artigo didatico, em que espusemos sucintamente - que o toque retal nos poderá fornecer de util, deixando mais uma vez consignado com clareza que esse metodo propedeutico deverá ser um exame de rotina.

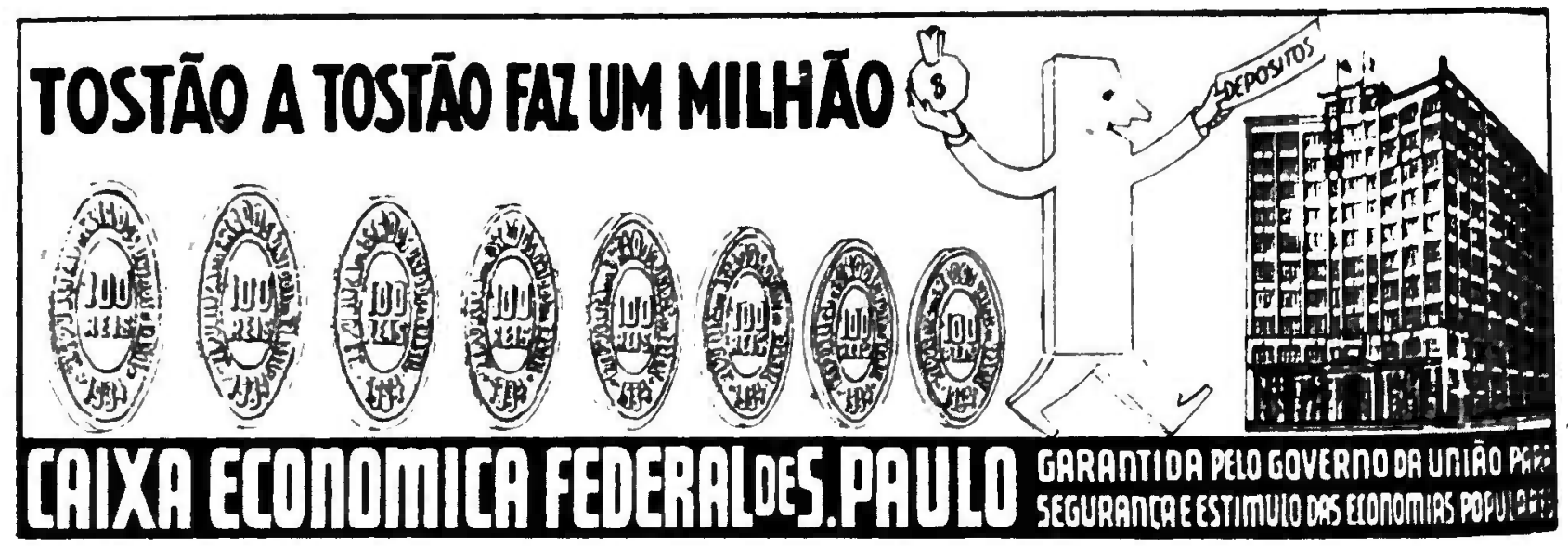




\section{A 4 HORAS DA CA P T A L encontram-se as AGUAS DE SÃO PEDRO a maravilha hidro-climática do Brasil}

Com suas 3 fontes de águas - sulfídrica, bicarbonatada e sulfatada - para tratamento do DIABETE, REUMATISMO, MOLÉSTIAS DA PELE, DO FIGADO, DOS RINS, DOS INTESTINOS E DO ESTOMAGO.

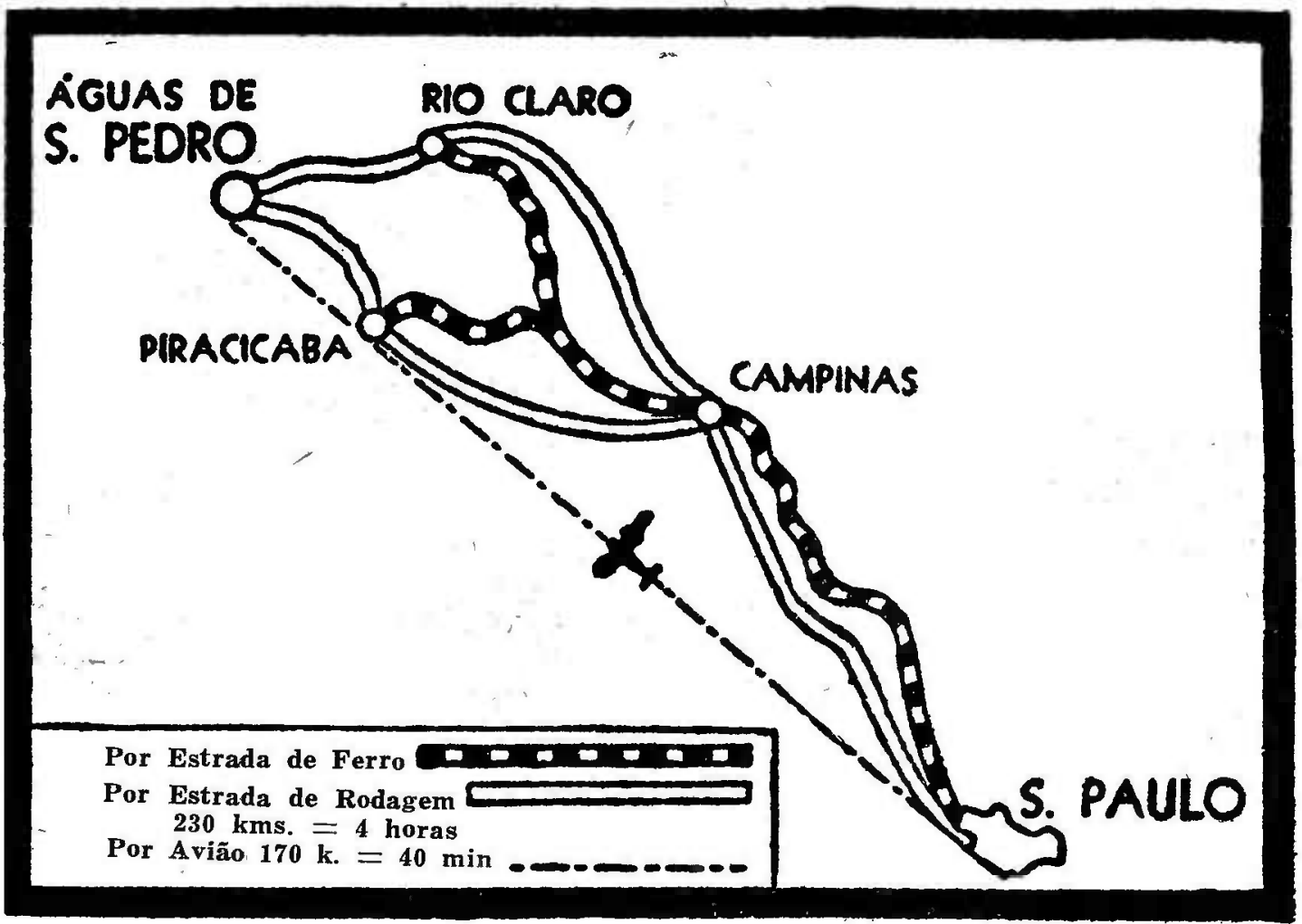

As ÁGUAS DE SÃO PEDRO possuem confortável HOTEL com 180 apartamentos e com cosinha dietética para os hospedes em regimem, sob controle do médico da Estância, além de magnífico CASSINO, recentemente inaugurado. Faça, pois, uma estação nesse aprasîvel e saudável recanto do Estado de São Paulo hospedando-se no

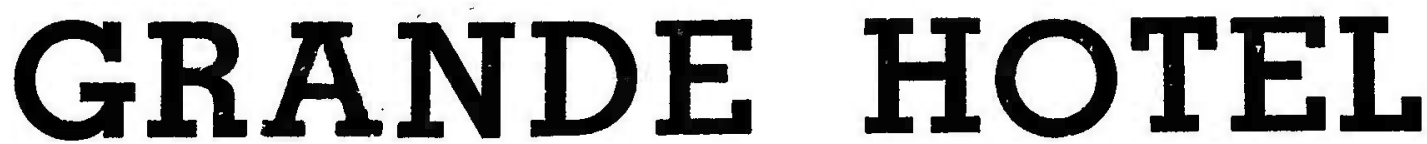

Reserve seus aposentos por intermédio do escritório em São Paulo: LARGO DA MISERICORDIA, 23 - 11. ANDAR

(Edificio "Ouro Para o Bem de São Paulo") TELEFONE, 3-5712 


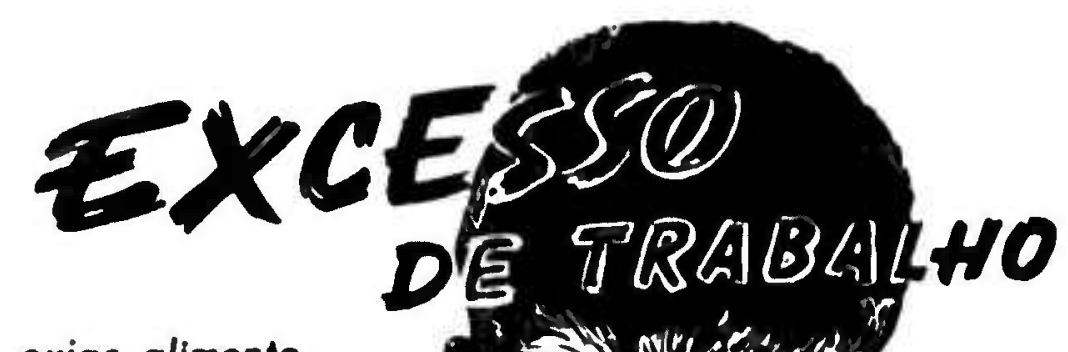

- estimulo d celula nervosa

\section{Nergofon}

hexapentenolcarboxil-hipotosfito de cilcio

encerrondo $35 \mathrm{mg}$ de fósforo elementor por ampolo de 2 cme. em combinocỏo orgonocókico, exerce esso dupla ocảo de maneiro róplida • durodouro.

\section{AMOSTRAS}

a disposingo dos

Srs. Médicos

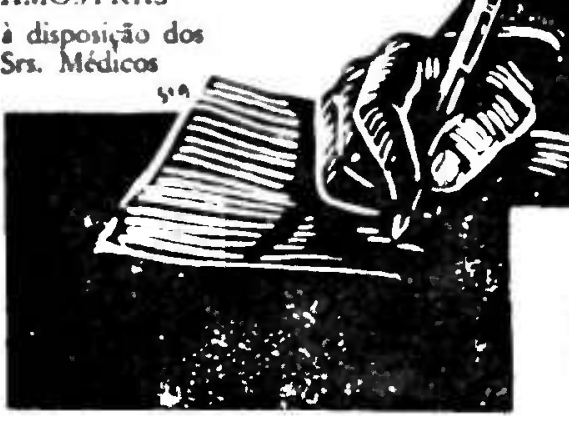

\section{DE TRABQBLAO}

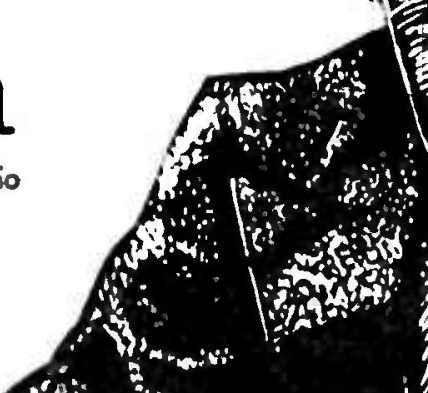
$\angle=2=5 \mathrm{~V}$
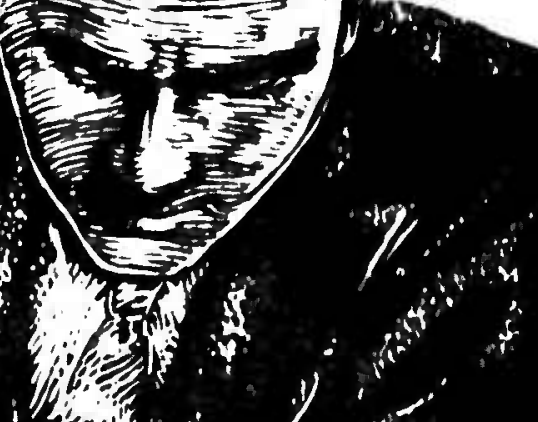

I NSTITUTO MEDIC A MENTA ESTABELECIMENTO CIENTIFICO INDUSTRIAL FONTOURA \& SERPE - SÃO PAULO - BRASIL

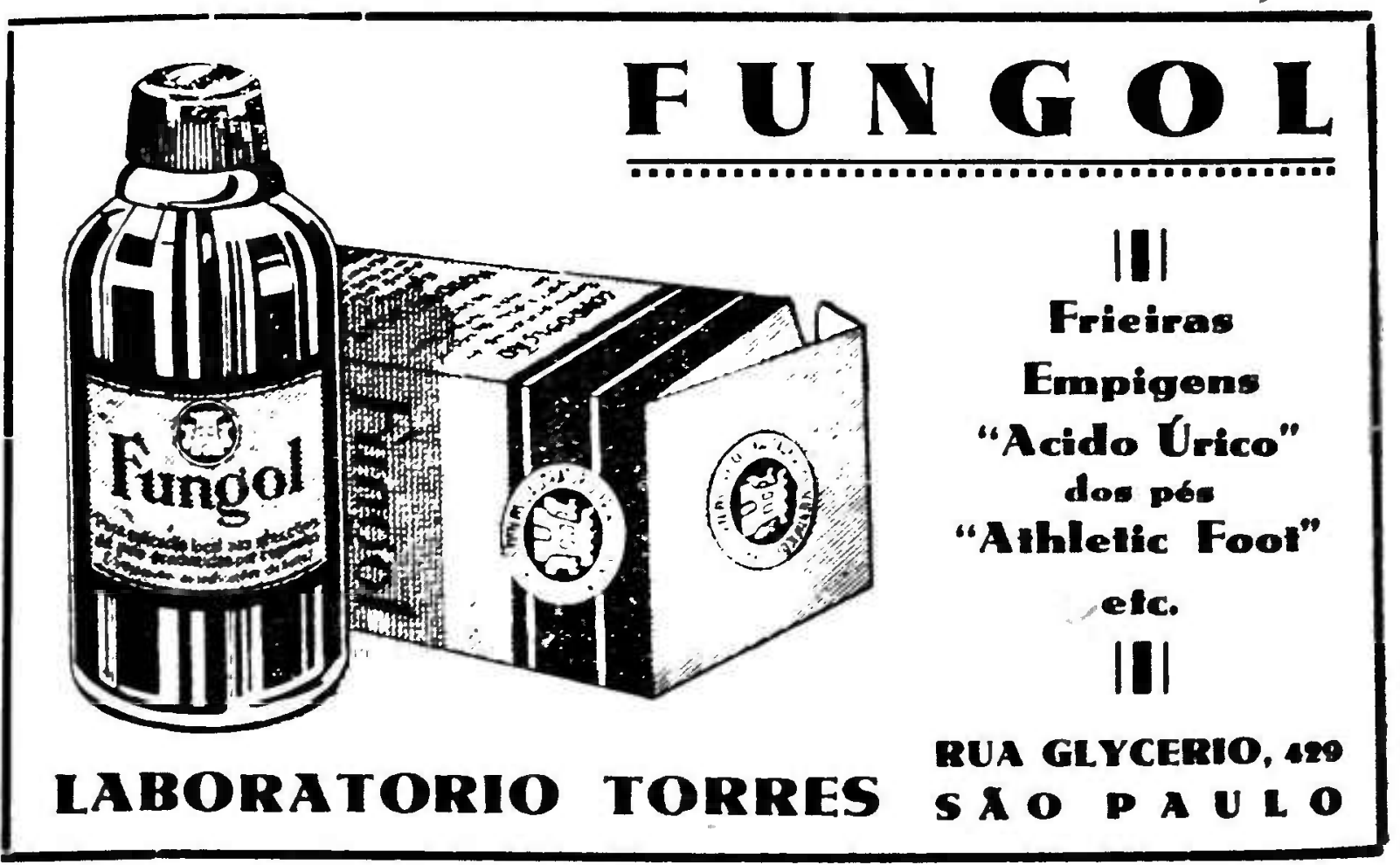

